\title{
A study investigating safety and pharmacokinetics of S-oxiracetam injection in healthy volunteers
}

\author{
Dahu Liang ${ }^{1}$, Haitang Xie ${ }^{1}$, Hua Sun ${ }^{1}$, Yuanwei Jia ${ }^{1}$, Min Dai ${ }^{1}$, Jing Shao ${ }^{1}$, Yan Jiang ${ }^{1}$, \\ Xianghong $\mathrm{Li}^{1}$, Bin Yang ${ }^{1}$, and Jie Shen ${ }^{1}$ \\ ${ }^{1}$ Affiliation not available
}

October 15, 2020

\begin{abstract}
Objective: To study the safety and pharmacokinetic (PK) profile of S-oxiracetam (S-ORT) in healthy volunteers, so as to provide a safe and reasonable basis for the application of formulation in phase II clinical programs. Methods: In part 1, subjects were intravenously administered single-ascending dose (2.0-8.0g) S-ORT. In part 2, subjects were treated by two-sequence, two-period crossover design. In part 3, subjects were intravenously injected with $4.0 \mathrm{~g}$ S-ORT once a day for 7 days. The biological samples were collected to evaluate the PK parameters and urine excretion rate. The safety profile of the drug was also evaluated throughout the test process. Results: Only 1 subject displayed a mild AE (adverse event) without obvious dosage-related AE, and SAE (serious adverse event). Within the range of 2.0-8.0 g for a single dose, Cmax, AUC0-t, and AUC0-[?] increased with an increase of dosage. The urine excretion rate of the prototype drug was approximately $60 \%$. The consecutive administration of drug could not cause a substantial accumulation of S-ORT. The plasma drug concentration-time curves for both S-ORT and R-oxiracetam (R-ORT) were found to be almost identical. Conclusions: The safety, tolerance and PK characteristics of S-ORT in the healthy volunteers within a range of 2.0-8.0 $\mathrm{g}$ for a single dose, or with $4.0 \mathrm{~g}$ for 7 consecutive days were found to be acceptable. The pharmacokinetics of S-ORT and racemic oxiracetam (ORT) were observed to be basically the same. The injection of S-ORT can be used at once-a-day dosing regimen for Phase II clinical studies.
\end{abstract}

A study investigating safety and pharmacokinetics of S-oxiracetam injection in healthy volunteers

Dahu Liang ${ }^{\# 1}$, Hua Sun ${ }^{\# 1}$, Yuanwei Jia ${ }^{1}$, Min Dai ${ }^{1}$, Jing Shao ${ }^{2}$, Yan Jiang ${ }^{2}$, Xianghong $\mathrm{Li}^{1}$, Bin Yang 1 , Jie Shen ${ }^{* 1}$, and Haitang Xie ${ }^{* 1}$

${ }^{1}$ Anhui Provincial Center for Drug Clinical Evaluation, Yijishan Hospital of Wannan Medical College, Wuhu, Anhui Province, 241001, China

2 Nanjing Youke Biomedical Co. LTD, Nanjing, Jiangsu Province, 210046, China

\section{*Corresponding author:}

xiehaitang@sina.com (Haitang Xie), shenjie-yjs@qq.com (Jie Shen)

\#These authors contributed equally to this work.

The authors confirm that the PI for this paper is Haitang Xie and that he had direct clinical responsibility for patients.

Running head: S-oxiracetam, Phase I

Keywords:S-oxiracetam; safety; pharmacokinetics; chirality; dose proportionality

Word count: 4000 
Tables count: 6

Figure count: 6

Abstract

Objective : To study the safety and pharmacokinetic (PK) profile of S-oxiracetam (S-ORT) in healthy volunteers, so as to provide a safe and reasonable basis for the application of formulation in phase II clinical programs.

Methods: In part 1, subjects were intravenously administered single-ascending dose (2.0-8.0g) S-ORT. In part 2, subjects were treated by two-sequence, two-period crossover design. In part 3, subjects were intravenously injected with $4.0 \mathrm{~g}$ S-ORT once a day for 7 days. The biological samples were collected to evaluate the PK parameters and urine excretion rate. The safety profile of the drug was also evaluated throughout the test process.

Results: Only 1 subject displayed a mild AE (adverse event) without obvious dosage-related AE, and SAE (serious adverse event). Within the range of 2.0-8.0 g for a single dose, $\mathrm{C}_{\max }, \mathrm{AUC}_{0-\mathrm{t}}$, and $\mathrm{AUC}_{0-[?]}$ increased with an increase of dosage. The urine excretion rate of the prototype drug was approximately $60 \%$. The consecutive administration of drug could not cause a substantial accumulation of S-ORT. The plasma drug concentration-time curves for both S-ORT and R-oxiracetam (R-ORT) were found to be almost identical.

Conclusions: The safety, tolerance and PK characteristics of S-ORT in the healthy volunteers within a range of 2.0-8.0 g for a single dose, or with $4.0 \mathrm{~g}$ for 7 consecutive days were found to be acceptable. The pharmacokinetics of S-ORT and racemic oxiracetam (ORT) were observed to be basically the same. The injection of S-ORT can be used at once-a-day dosing regimen for Phase II clinical studies.

(248/250 words)

\section{WHAT IS ALREADY KNOWN ABOUT THIS SUBJECT}

- ORT has been widely used around the world for many years with significant curative effect and tolerable adverse effects. It was clinically used for the management of memory and intellectual impairment caused by mild to moderate vascular dementia, senile dementia, and brain trauma.

- Pre-clinical studies have shown that S-ORT is the main active ingredient in the ORT that can exert substantial pharmacological effects. In addition, the potential toxic and side effects can be reduced by decreasing the dosage when it has been used alone, which can also improve its efficacy, and thereby provide a more accurate information related to the toxicology/toxicokinetics and pharmacokinetic/pharmacodynamic relationship.

- All ORT used clinically are in the racemates form currently, and S-ORT for injection has not been listed and used around the world.

\section{WHAT THIS STUDY ADDS}

- This study revealed both the safety and pharmacokinetics of the improved formulation of a novel drug S-ORT in the healthy volunteers for the first time.

- Overall, the good safety and appropriate pharmacokinetics of S-ORT in humans can provide a rationale for the safe and reasonable basis for the application of this formulation in phase II clinical programs.

\section{Introduction}

Oxiracetam (ORT), whose chemical name is 4-hydroxy-2-oxo-1-pyrrolidine acetamide, is the $\beta$-hydroxy derivative of Piracetam. It has been clinically used to treat various cognitive dysfunctions, improve learning ability, as well as promote and enhance memory ${ }^{[1-6]}$. Through the interaction with glutamate receptors, ORT can selectively act on the cerebral cortex and hippocampus to protect, activate or promote the recovery of nerve cell functions. However, the drug itself does not display any direct vascular and central excitatory effects, and the impact of ORT on learning and memory has been reported to be long-lasting one ${ }^{[7-8]}$. In 
addition, this product has been reported to exert a positive protective effects on craniocerebral trauma, cerebrovascular injury, and mild to a moderate multiple cerebral infarction dementia ${ }^{[9]}$. ORT molecule contains an asymmetric carbon atom at the $4^{\text {th }}$ position of the pyrrole ring, which can exist in the two isomer forms: S-ORT and R-ORT ${ }^{[10]}$, and the chemical structural formulas of these two isomers has been shown in Fig. 1.

Chirality is essential for various biological activities, and most of the active compounds are chiral molecules [11]. The chemical and physical properties of chiral molecules are basically the same, while the biological activity, mechanism of action and toxicity of one form of the enantiomer drug may differ drastically ${ }^{[12-13]}$. ORT, as a "racetam" nootropic drug, can exhibit significant stereospecificity, and subtle differences in structure that can lead to significant changes in its pharmacological activities ${ }^{[14]}$. Previous studies ${ }^{[15]}$ have found that the effects of S-ORT was significantly better than that of the R-ORT, when inducing and enhancing the long-term potentiation effect of rat hippocampal slices. Additionally, in the presence of glutamate, S-ORT could also stimulate $\mathrm{Ca}^{2+}$ to be taken up into the cerebellum in a dose-dependent manner, while R-ORT was found to be ineffective ${ }^{[16]}$. Recent studies ${ }^{[17-18]}$ have shown that compared with R-ORT, S-ORT is the major active ingredient of ORT, which can reduce cognitive impairment caused by chronic cerebral hypoperfusion in the rats. The data also suggested that only S-ORT administration was beneficial for treatment. Therefore, the development of one single isomer of S-ORT could help to significantly reduce drug dose, decrease toxicity, improve efficacy, and provide a more precise relationship about toxicology/toxicokinetics and pharmacokinetic/pharmacodynamic ${ }^{[19]}$.

Although the use of S-ORT alone may have several advantages as elaborated above, only racemic ORT is in clinical use currently, and there are no reports related to the clinical application of S-ORT. Therefore, this study for the first time explored the PK characteristics of S-ORT used as an injection in healthy volunteers, analyzed the PK of single and multiple-dose injection, and also compared the PK difference of the two enantiomers. At the same time, the safety and tolerance of this product was also carefully evaluated, thereby providing a safe and reasonable basis for the clinical use of this formulation in phase II clinical programs.

2. Methods

\subsection{Study design}

The study was a randomized, open, single-arm phase I clinical trial and was divided into three parts (Fig. 2): Part 1 (single-dose administration), the subjects were randomly divided into three different groups with 10 people in each group, and they were injected with $2.0 \mathrm{~g}, 4.0 \mathrm{~g}$, and $8.0 \mathrm{~g}$ S-ORT by intravenous infusion, respectively. Each subject only received one dosage of the drug, and after obtaining the results of clinical observations and laboratory examinations of the previous dosage, if no unacceptable AE was found, the next dose was administered. For the $4.0 \mathrm{~g}$ group, the urine was also collected to calculate the cumulative excretion rate. In part 2 (comparison of chirality PK), 12 subjects were randomly divided into two groups, one of which was injected with $3.0 \mathrm{~g}$ S-ORT by intravenous infusion during the first period, thereafter, 6.0 g racemic ORT was injected after a 7-day washout period. For the other group, the subjects were first injected with $6.0 \mathrm{~g}$ racemic ORT, and then subsequently injected with $3.0 \mathrm{~g}$ S-ORT. In part 3 (multiple-dose administration), 10 subjects were intravenously instilled with $4.0 \mathrm{~g}$ S-ORT once a day consecutively for 7 days. The ratio of male to female in each group was 1:1.

The volunteers who were screened and qualified for inclusion in the various groups were monitored by the clinicians during their participation in the clinical trial. The trial site was located in the Phase I clinical research ward of Yijishan Hospital of Wannan Medical College. During the trial, subjects were advised to avoid strenuous activities, and abstain from smoking, drinking alcohol or other caffeine and carbonated (e.g., tea, chocolate, coke) drinks. The physical and laboratory examination results of the subjects were recorded before and after the test (e.g., blood routine, urine routine, stool routine, blood biochemistry and related inspection).

2.2 Participants 
The study was approved by the former State Food and Drug Administration (SFDA), and the batch number was 2013L02096. The trial strictly abided by the rules specified in "Helsinki Declaration" and "Quality Control of Clinical Trial of Drugs" as issued by SFDA. The research protocol and its various amendments, the investigator's manual, the informed consent and the subject recruitment materials were carefully reviewed and approved by the ethics committee of Yijishan Hospital of Wannan Medical College. The eligibility criteria were as follows: Healthy male and female volunteers with age of 18-40, and with body mass index ranging from 19-24 were included in this study. Thereafter, based on the medical history, screening tests (e.g., electrocardiogram, blood routine, blood biochemistry, urine routine, serum virology examination and physical examination), qualified volunteers were included in the trial. However, pregnant and lactating women, people with a history of drug dependence or mental illness in the past two years, volunteers who have participated in other drug clinical trials 3 months before the test were excluded from this study. Besides, those who were found allergic to the drugs and food, and positive for anti-HIV, anti-HCV, HBsAg tests were also excluded.

\subsection{Drugs}

S-ORT for injection packed in $1 \mathrm{~g} /$ bottle (batch number: 20140401), was produced by Nanjing Youke Pharmaceutical Co., Ltd., and provided by Nanjing Youke Biomedical Research Co., Ltd. ORT for injection was $1 \mathrm{~g}$ /bottle (batch number: 262131043), produced by Shiyao Group Ouyi Pharmaceutical Co., Ltd., and was provided by Nanjing Youke Biomedical Research Co., Ltd.

\subsection{Safety assessments}

For Part 1 and Part 2, the blood pressure, pulse, respiration, and temperature of subjects were measured at $1,2,4,6,8,12,24,48 \mathrm{~h}$ before and after the drug administration. The complaints and positive signs of the subjects were also observed and recorded. In Part 3, vital signs were measured at 1, 2, 4, 6, 8, $12 \mathrm{~h}$ before and after administration from day 1 to day 6 . At day 7 , the time points of vital signs detection were similar to Part 1 tests. The complaints and positive signs of the subjects were again observed and recorded. In addition, examinations of all the subjects, including physical examinations, blood routine, blood biochemistry, urine routine, stool routine and occult blood test, coagulation function, electrocardiogram and other examinations were performed upon entering and leaving the group. During the entire study period, the occurrence of AEs was carefully recorded, and the severity, duration, results, and possible relationship with drug administration were evaluated. All the safety data was properly analyzed by detailed statistical analysis.

\subsection{Blood and urine sampling}

For Part 1 and Part 2, $4 \mathrm{~mL}$ venous blood was carefully collected before administration $(0 \mathrm{~h})$ and after administration $0.17,0.33,0.50,0.75,1.0,1.5,2.0,3.0,4.0,6.0,8.0,10.0,12.0,24.0 \mathrm{~h}$. For part1 $4.0 \mathrm{~g}$ dose group, the urine samples of the subjects were collected before administration $(0 \mathrm{~h})$, and after administration at different time intervals $0-4,4-8,8-12,12-24,24-36$ and 36-48 $\mathrm{h}$. Thereafter, the amount of urine at each time was recorded. 5-10 mL urine was collected and stored at -70 for further sample analysis. For part 3, 0.4 $\mathrm{mL}$ venous blood was collected on day 1 and day 7 before administration $(0 \mathrm{~h})$ and after administration at various time points such as $0.17,0.33,0.50,0.75,1.0,1.5,2.0,3.0,4.0,6.0,8.0,10.0,12.0,24 \mathrm{~h} .4 \mathrm{~mL}$ blood samples of trough concentration were collected on day 5 and day 6 before administration. All the collected blood samples were placed in the heparinized centrifuge tubes, centrifuged at $3500 \mathrm{rpm}$ for 5 minutes, and the upper layer of plasma was frozen and stored at -70 for sample analysis.

\subsection{Bioanalytical methods}

Plasma and urine sample in part1 and part3Instruments: API3200 mass spectrometer (Applied Biosystems Sciex, USA), Analyst 1.4.2 data processing software;Chromatographic conditions: Lichrospher $\mathrm{C}_{18}(4.6 \mathrm{~mm} \times 150 \mathrm{~mm}, 5 \mu \mathrm{m})$ chromatographic column; Mobile phase: acetonitrile-water phase (The aqueous phase contained $10 \mathrm{mmol}[?] \mathrm{L}^{-1}$ ammonium acetate and $0.1 \%$ formic acid) (85:15). Mass spectrometry conditions: electrospray ionization source (ESI), positive ion detection mode. The compound parameters for S-ORT: parent ion: $\mathrm{m} / \mathrm{z}$ 159.1, daughter ion: $\mathrm{m} / \mathrm{z}$ 114.0; Piracetam (IS): parent ion: m/z143.0, 
daughter ion: $\mathrm{m} / \mathrm{z} 126.0$. Plasma sample processing: plasma samples were treated by precipitating the protein with acetonitrile, and analyzed by HPLC-MS/MS. Urine sample processing: urine samples was diluted with methanol after being treated by precipitating the protein with methanol and then analyzed by HPLC-MS/MS.

Plasma sample in part2 Instrument : Waters high performance liquid chromatography (HPLC), Waters Empower processing software; Chromatographic conditions : CHIRALPAK ${ }^{\circledR}$ ID $(4.6 \mathrm{~mm} \times 250 \mathrm{~mm}, 5 \mu \mathrm{m})$ chromatographic column; Mobile phase: n-hexane-anhydrous ethanol (anhydrous ethanol contained $0.1 \%$ trifluoroacetic acid) (82:18); UV detection wavelength: $210 \mathrm{~nm}$. Plasma sample processing:after the plasma samples were precipitated protein by acetonitrile, the entire supernatant was blown dry with nitrogen, dissolved in $300 \mu \mathrm{L}$ mobile phase and then transferred into sample bottle for HPLC analysis.

For part 1 and part 3 , the linearity of plasma concentration measurement was found to be $0.5-400 \mu \mathrm{g}[?] \mathrm{mL}^{-1}$, and the urine concentration was found in the range of $20-2000 \mu \mathrm{g}[?] \mathrm{mL}^{-1}$. For part 2, the linearity of plasma concentration measurement was $5-400 \mu \mathrm{g}[?] \mathrm{mL}^{-1}$. The samples that exceeded the limitation of linearity were diluted and then further analyzed. The analysis method was carried out very carefully, exactly met the requirements of the verification guidelines for biological sample analysis as issued by FDA, and all verification parameters were noted to be within the acceptable range.

\subsection{Pharmacokinetic data analysis}

The blood concentration of S-ORT at different time points was analyzed by DAS2.1 software (version 2.1, China) to calculate the PK parameters of non-compartmental model. The maximum plasma concentration $\left(\mathrm{C}_{\max }\right)$ and the time to reach $\mathrm{C}_{\max }\left(\mathrm{T}_{\max }\right)$ was obtained directly from the observed plasma concentrations. The elimination rate constant $\mathrm{k}_{\mathrm{e}}$ was obtained from the terminal slope of the semi-logarithmic drug concentration-time curve. The elimination half-life time $\mathrm{T}_{1 / 2}$ was calculated with $\ln 2 / \mathrm{k}_{\mathrm{e}} . \mathrm{AUC}_{0-\mathrm{t}}$ was determined by the linear trapezoidal method from the area under the curve within the time from administration to the lowest blood concentration that could be detected. $\mathrm{AUC}_{0-[?]}$ was the area under the curve from administration to extrapolation to infinity. In the formula: $\mathrm{AUC}_{0-[?]}=\mathrm{AUC}_{0-\mathrm{t}}+\mathrm{C}_{\mathrm{t}} / \mathrm{k}_{\mathrm{e}}, \mathrm{C}_{\mathrm{t}}$ was the last measurable concentration. Clearance rate $\mathrm{CL}_{\mathrm{z}}=\mathrm{D} / \mathrm{AUC}_{0-[?]}$ (D was dose). $\mathrm{V}_{\mathrm{z}}=\mathrm{CL} / \mathrm{k}_{\mathrm{e}}$. $\mathrm{AUC}_{\mathrm{ss}}$, the $\mathrm{AUC}$ at steady state, was equal to $\mathrm{AUC}_{0-\tau}$ (multiple doses), which was calculated by the trapezoidal method within the dosing interval $\tau$. At steady state, trough concentration $\mathrm{C}_{\mathrm{ss}, \min }$ and peak concentration $\mathrm{C}_{\mathrm{ss} \text {, max was directly }}$ obtained from the measured plasma concentration-time data. The average steady-state plasma concentration of $\mathrm{C}_{\mathrm{av}}$ was found to be equal to $\mathrm{AUC}_{\mathrm{ss}} / \tau$. The fluctuation coefficient $\mathrm{DF}=\left(\mathrm{C}_{\max }-\mathrm{C}_{\min }\right) / \mathrm{C}_{\mathrm{av}} \times 100 \%$. The accumulation index $R_{a c}$ was calculated based on the ratio of the measured value of $\mathrm{AUC}_{\mathrm{ss}}$ on the 7 th day in relation to the measured value of $\mathrm{AUC}_{0-24 \mathrm{~h}}$ on the 1st day, and the formula used was $\mathrm{R}_{\mathrm{ac}}=\mathrm{AUC}_{\mathrm{ss}} / \mathrm{AUC}_{0-24 \mathrm{~h}}$ (single dose). The urine concentration data was used to determine the cumulative excretion rate of the drug within the last 48 hours.

\subsection{Statistics}

The descriptive statistical analysis was performed on the number of selected subjects, dropouts and removals, demographic statistics and other baseline characteristics. The safety analysis used descriptive statistical methods to analyze the degree of $\mathrm{AE}$, the relationship between duration and drug administration, and outcomes were analyzed on a case-by-case basis. The incidence rate, number and frequency of AE and other adverse reactions were also carefully calculated. The main PK difference between the three doses of a single administration was analyzed by one-way analysis of variance, and the dose-proportion relationship about the main PK parameters was analyzed by Power Model ${ }^{[20-21]}$. The model formula used was: ln (PK parameter) $=\alpha+\beta^{*} \ln \left(\right.$ Dose), and the PK parameters included $\mathrm{C}_{\max }$ and AUC, $\alpha$ was the intercept, $\beta$ was the slope. The linear relationship was evaluated according to the $90 \%$ confidence interval (CI) of the slope $\beta$. If the CI value included 1, the relationship of non-linear dose-proportion was considered as not significant, while the linear dose-proportion relationship could be established. If the CI was entirely within the judgment interval, the PK parameter and dose were found to display a linear PK characteristic. If the CI was noted to be entirely outside the judgment interval, within the given dose range, the PK parameter and dose were not considered 
to display a linear PK characteristic. If the CI overlapped with the judgment interval, a defined conclusion could not be given within the administered dose range. The PK parameters correlation between Part1 and Part3 and the PK difference between male and female were analyzed using group $t$-test. The paired $t$ - test was used to analyze the PK parameters of S-ORT after two periods of intravenous infusion with $3.0 \mathrm{~g}$ S-ORT and $6.0 \mathrm{~g}$ racemic ORT. The sample size of the study was the standard conventional sample size used for evaluating the safety and PK characteristics in the phase I clinical study, and was not calculated based on statistical power.

\section{Results}

\subsection{Subject disposition and demographics}

The 52 subjects included in the study completed the study as planned, and no cases dropped in or were eliminated during the study. There was no significant difference noted in the baseline value of each treatment group. The demographical and baseline characteristics of the study subjects have been shown in Table 1 .

\subsection{Safety}

At the end of each dose group, physical examination, vital signs, electrocardiogram and laboratory test indicators (blood routine, urine routine, blood biochemistry, blood coagulation function, etc.) of subjects did not show significant clinical changes. 4 subjects (3 in Part $14.0 \mathrm{~g}$ group, 1 in Part $18.0 \mathrm{~g}$ group) showed abnormal laboratory test indicators, which was further analyzed by the doctor and found to have no clinical significance. The 4 subjects came to review on time and confirmed that they were back to normal state. 1 subject in the Part1 8.0 g group showed abnormal urine test, which was related to menstrual cycle, and returned to normal after 4 days. During the trial, 1 mild AE occurred, that is, 1 subject in Part 3 had abdominal distension and discomfort on the $4^{\text {th }}$ day of the trial, which was naturally resolved without any medication or other treatments. The study doctor concluded that the AE might be related to the drug. During the study, no other SAE occurred in any other group of the subjects.

\subsection{Pharmacokinetics}

The PK parameters of each dose group of part1 have been shown in Table 2. One-way analysis of variance was used to analyze the PK parameters between the groups, and the results showed that the main PK parameters, such as $\mathrm{T}_{1 / 2}$ and $\mathrm{V}_{\mathrm{z}}$, between the dose groups were not statistically significant $(\mathrm{p}>0.05)$. However, $\mathrm{C}_{\max }$, $\mathrm{AUC}_{0-\mathrm{t}}$, and $\mathrm{AUC}_{0-[?]}$ increased upon increasing the drug dose, and the difference between groups was statistically significant $(\mathrm{p}<0.05)$. The average drug concentration-time curve of the three dose groups in part 1 has been shown in Fig. 3. From the log-averaged drug concentration-time curve, it could be clearly seen that the elimination rates of the three dose groups were basically the same. The linear regression was performed with dose as abscissa, and with $\mathrm{C}_{\max }, \mathrm{AUC}_{0-\mathrm{t}}$, and $\mathrm{AUC}_{0-[?]}$ as ordinates. After spearman correlation analysis, the correlation coefficient of $\mathrm{C}_{\max }$-dose was $0.940, \mathrm{P}<0.001$. The correlation coefficient of $\mathrm{AUC}_{0-\mathrm{t}}$-dose was noted to be $0.941, \mathrm{P}<0.001$. The correlation coefficient of $\mathrm{AUC}_{0-[?]-\text { dose was observed to }}$ be $0.937, \mathrm{P}<0.001$. The results showed that $\mathrm{C}_{\max }, \mathrm{AUC}_{0-\mathrm{t}}$, and $\mathrm{AUC}_{0-[?]}$ increased with increasing dose, and had a linear correlation with dose. The power model was used to evaluate the linearity of PK parameters and dose. $\mathrm{C}_{\max }, \mathrm{AUC}_{0-\mathrm{t}}$ and $\mathrm{AUC}_{0-[?]}$ were fitted to the dose by the power model formula $\ln (\mathrm{PK})=\alpha+\beta^{*} \ln$ (Dose), and the $\beta$ values (90\% CI) were 0.837 (0.733-0.942), $0.822(0.710-0.934)$, and 0.810 (0.696-0.923), respectively. For $\mathrm{C}_{\max }, \mathrm{AUC}_{0-\mathrm{t}}$ and $\mathrm{AUC}_{0-[?]}, 90 \% \mathrm{CI}$ of $\beta$ value did not contain 1, indicating that in the 2.0-8.0 g dose interval, $\mathrm{C}_{\max }, \mathrm{AUC}_{0-\mathrm{t}}$ and $\mathrm{AUC}_{0-[?]}$ of S-ORT increased upon increasing dose, whereas $\mathrm{C}_{\max } /$ dose, $\mathrm{AUC}_{0-\mathrm{t}} /$ dose, and $\mathrm{AUC}_{0-[?]} /$ dose showed a significant decreasing trend.

Among them, urine of $4.0 \mathrm{~g}$ group was collected. Urinary cumulative excretion rate at $48 \mathrm{~h}$ after S-ORT administration was $59.99 \% \pm 5.41 \%$. The urinary excretion rate data and profile has been shown in Fig. 4 . The results clearly indicated that most of the S-ORT was excreted through the urine, and the proportion was approximately $60 \%$.

The trough concentrations before blood sampling from day 5 to day 7 , and $24 \mathrm{~h}$ after administration has been shown in Table 3. As depicted in the table, the trough concentrations were almost similar, and analyzed 
using analysis of variance. The results showed that there was no statistically significant difference $(\mathrm{P}>0.05)$ and indicated that a steady state can be reached with a dose once a day for 5 days.

For $4.0 \mathrm{~g}$ multiple-dose group, the PK data on $1^{\text {st }}$ day and $7^{\text {th }}$ day after administration was compared, and paired $t$ - test was used to analyze the PK parameters. As shown in Table 4, the main PK parameters, such as $\mathrm{T}_{1 / 2}, \mathrm{C}_{\max }\left(\mathrm{C}_{\mathrm{ss}-\mathrm{max}}\right), \mathrm{AUC}_{0-\mathrm{t}}\left(\mathrm{AUC}_{\mathrm{ss}}\right)$, and $\mathrm{AUC}_{0-[?]}$ displayed no significant difference between day 1 and day $7(\mathrm{P}>0.05)$. The average drug concentration-time curve of the $4.0 \mathrm{~g}$ multiple-dose group on day 1 and day 7 has been shown in Fig.5. From the Fig.5, it can be clearly noted that the drug concentration-time curves of single and multiple doses were basically the same when attaining a steady state. In addition, upon comparing the logarithmic scale drug concentration-time curves, their eliminations were found to be basically the same. The accumulation index $\mathrm{R}_{\mathrm{ac}}$ was calculated based on the ratio of the measured value of $\mathrm{AUC}_{\mathrm{ss}}$ after attaining a steady state on the day 7 to the calculated value of $\mathrm{AUC}_{0-24 \mathrm{~h}}$ on day 1 , and the result was noted to be 1.05(0.08). The accumulation index was $1.08(0.06)$, which was calculated with the formula $R_{a c}=1 /\left(1-e^{-\varkappa \varepsilon^{*} \tau}\right)$. Both of them were found to be basically the same and approximately close to 1 , thereby indicating that S-ORT could not cause significant accumulation in body with a once-a-day dosing regimen.

To analyze the effects of gender on $\mathrm{PK}$, the various $\mathrm{PK}$ parameters $\left(\mathrm{C}_{\max }, \mathrm{AUC}_{0-\mathrm{t}}, \mathrm{AUC}_{0-[?]}, \mathrm{T}_{1 / 2}, \mathrm{~T}_{\max }\right.$, $\mathrm{V}_{\mathrm{z}}, \mathrm{CL}_{\mathrm{z}}$ ) of Part1 and Part3 were subjected to a group based on genders for $t$ - test, and the results have been shown in Table 5. The results indicated that $\mathrm{C}_{\max }, \mathrm{AUC}_{0-\mathrm{t}}, \mathrm{AUC}_{0-[?]}$, and $\mathrm{CL}_{\mathrm{z}}$ in the $2.0 \mathrm{~g}$ dose group of part1, $\mathrm{V}_{\mathrm{z}}$ of part3 on day 1 , and $\mathrm{AUC}_{\mathrm{ss}}, \mathrm{AUC}_{0-[?]}, \mathrm{CL}_{\mathrm{z}}$ of part3 on day 7 showed significant differences between the genders $(\mathrm{P}<0.05)$. The gender differences in the $\mathrm{PK}$ parameters of the remaining dose groups can be ignored $(\mathrm{P}>0.05)$.

The paired $t$-test was used to analyze the PK difference of S-ORT after intravenous infusion of $3.0 \mathrm{~g}$ SORT and $6.0 \mathrm{~g}$ racemic ORT. The results have been shown in Table 6. The drug concentration-time curves of S-ORT and R-ORT after intravenous instillation of $6.0 \mathrm{~g}$ ORT were almost identical, as shown in Fig. 6. The results suggested that the two kinds of ORT isomers in the body had no obvious interactions and conversions.

\section{Discussion}

ORT has been used safely in the past, with only few reports related to major adverse reactions ${ }^{[1,22-23]}$, and patients may develop anxiety, skin itching, rash, nausea, stomach pain, etc., which can subside by itself after discontinuing the drug. The active ingredient of this product is the S-ORT, which is an improved drug with relatively low risk, and without any reports of obvious dose-related AE occurring in the study. During the trial, 1 subject in Part 3 showed abdominal distension and discomfort on day 4. Interestingly, previous reports have indicated that administration of ORT racemates could cause nausea, vomiting, stomach upset and other adverse reactions ${ }^{[24]}$. Therefore, it was hypothesized that the correlation between $\mathrm{AE}$ and the drug was "possibly related", but a detailed analysis may be required. The severity of AE was mild, and SAE did not occur during this study.

To establish a chiral separation method for ORT racemates, several reversed-phase and normal-phase chromatography systems have been carefully evaluated. When a reversed-phase system was used, the ORT enantiomers could be properly separated at the baseline. As a consequence, the normal phase system of Chiralpak ${ }^{\circledR}$ ID chiral column for chromatographic separation was used. However, the mobile phase in the normal phase system can be associated with major disadvantages such as potential explosion hazard and poor ionization in the mass spectrometry ion source ${ }^{[25-26]}$. Therefore, the chiral separation was performed on Waters HPLC.

Currently, there are no specific requirements for the sample size to conduct the safety and PK study in the phase I clinical trials of drugs. The sample size of this study is the regular sample size employed in a phase I clinical study for evaluating safety and PK, and is not calculated based on the statistical power. However, it is considered more optimal if the number of subjects can answer their potential research purposes. 
The variance analysis model of dose-proportion correlation analysis (Table 2) showed that the ratios of the mean exposures of three dose groups (low, middle and high) were 1:2.07:3.17 $\left(\mathrm{C}_{\max }\right), 1: 1.96: 3.08\left(\mathrm{AUC}_{0-\mathrm{t}}\right)$, and 1:1.91:2.99 $\left(\mathrm{AUC}_{0-[?]}\right)$, respectively. The values of $\mathrm{C}_{\max } /$ dose, $\mathrm{AUC}_{0-\mathrm{t}} /$ dose, and $\mathrm{AUC}_{0-[?]} /$ dose in 8.0 $\mathrm{g}$ dose group were observed to be relatively lower. This study applied the power model to analyze the does-proportion relationship, for $\mathrm{C}_{\max }, \mathrm{AUC}_{0-\mathrm{t}}$ and $\mathrm{AUC}_{0-[?]}, 90 \% \mathrm{CI}$ of $\beta$ values was found in the left of 1 . The CI and the judgment interval (calculated according to the bioequivalence criterion 0.80-1.25) overlapped substantially, and the defined conclusion could not be reached within the given dose range, which might be due to the parallel experimental design, small sample size in each dose group (only 10 cases in each group), and individual differences in the subjects enrolled for this study.

In Part 2, after dose correction, $\mathrm{C}_{\max }, \mathrm{AUC}_{0-\mathrm{t}}, \mathrm{AUC}_{0-[?]}$ were basically consistent with the results in part1, but $T_{1 / 2}$ and $V_{z}$ were found to be significantly lower. In the statistical moment model, $T_{1 / 2}$ was calculated by the elimination rate at the end of the drug concentration-time curve, and the last time point of sampling appeared to have a greater effect on the calculation results. However, due to the limitation of detection sensitivity (the LLOQ was observed to be $5 \mu \mathrm{g} / \mathrm{mL}$ in part 2). Moreover, the blood concentrations at $12 \mathrm{~h}$ and $24 \mathrm{~h}$ after administration in part2 were observed to be lower than LLOQ, and the end sampling time for PK parameter calculation in this group varied from $8 \mathrm{~h}$ to $10 \mathrm{~h}$, which might explain that both $\mathrm{T}_{1 / 2}$ and $\mathrm{V}_{\mathrm{z}}$ were noted to be relatively lower.

The prototype of this product was found to be mainly excreted through urine (excretion rate was about $60 \%$ ). However, the metabolism of this product in the body has not been extensively analyzed, and the follow-up study will further explore both the metabolism and the mass balance of S-ORT in accordance with the proper requirements.

In conclusion, this was the first phaseIclinical study to explore both the safety, tolerance and pharmacokinetics characteristics of the improved novel drug of S-ORT in the healthy Chinese volunteers. No safety concerns were identified with the single-dose intravenous infusion in a range of 2.0-8.0 g and multiple-dose administrations of $4.0 \mathrm{~g}$ for 7 consecutive days. These findings could provide valuable information for the further investigation of S-ORT injection in phase II clinical studies.

Acknowledgement

The authors wish to thank all subjects who participated in the studies, and internal and external project teams for their services.

Author Contributions

Clinical study design: H.T.X., J.S., J.S., Y.J.

Clinical study conduct: D.H.L., S.H., Y.W.J.

Pharmacokinetic study: D.H.L., H.S., M.D., X.H.L., B.Y.

Drafting manuscript: D.H.L., H.S.

Editing manuscript: D.H.L., H.S., H.T.X., J.S.

Conflict of Interest Statement

Y.J. and J.S. are employees of the study sponsor, Nanjing Youke Biomedical Co. LTD. D.H.L, H.S., Y.W.J., M.D., X.H.L., B.Y., J.S., H.T.X. are employees of Anhui Provincial Center for Drug Clinical Evaluation. Haitang Xie was Principal Investigator of the clinical studies.

Funding Information

The clinical studies were funded by Nanjing Youke Biomedical Co. LTD.

Data Availability Statement

Research data are not shared. 


\section{Reference}

1. Perucca E, Albrici A, Gatti G, Spalluto R, Visconti M, Crema A. Pharmacokinetics of oxiracetam following intravenous and oral administration in healthy volunteers. Eur J Drug Metab Pharmacokinet $1984 ; 9(3): 267-274$

2. Moglia A, Sinforiani E, Zandrini C, Gualtieri S, Corsico R, Arrigo A. Activity of oxiracetam in patients with organic brain syndrome: a neuropsychological study. Clin Neuropharmacol 1986; 9(3):73-78

3. Pugliese AM, Corradetti R, Ballerini L, Pepeu G. Effect of the nootropic drug oxiracetam on field potentials of rat hippocampal slices. Br J Pharmacol 1990; 99(1):189-193

4. Yao XL, Yao ZH, Li L, Nie L, Zhang SF. Oxiracetam can improve cognitive impairment after chronic cerebral hypoperfusion in rats.Psychiatry Res 2016; 246:284-292

5. Xu J, Qi QQ, Lv PY, Dong YH, Jiang X, Liu ZJ. Oxiracetam ameliorates cognitive deficits in vascular dementia rats by regulating the expression of neuronal apoptosis/autophagy-related genes associated with the activation of the Akt/mTOR signaling pathway. Braz J Med Biol Res 2019; 52(11): e8371

6. Zhang H, Jia LF, Jia JP. Oxiracetam Offers Neuroprotection by Reducing Amyloid $\beta$-Induced Microglial Activation and Inflammation in Alzheimer's Disease. Front Neurol 2020; 11:623

7. Hu SL, Shi JT, Xiong W, Li WN, Fang LC, Feng H. Oxiracetam or fastigial nucleus stimulation reduces cognitive injury at high altitude.Brain Behav 2017; 7(10): e00762

8. Huang LL, Shang Ex, Fan WX, Li X, Li BB, He SC, Fu YX, Zhang YZ, Li YM, Fang WR. S-oxiracetam protect against ischemic stroke via alleviating blood brain barrier dysfunction in rats. Eur J Pharm Sci 2017; 109: 40-47

9. Wang CY, Li FQ, Guan Y, Zhu L, Fei YP, Zhang JD, Pan YJ. Bone marrow stromal cells combined with oxiracetam influences the expression of B-cell lymphoma 2 in rats with ischemic stroke. Stroke Cerebrovasc. Dis 2014; 23(10): 2591-2597

10. Sanyal I, Shukla B, Barman PD, Banerjee AK. Stereoselective synthesis of (S)-oxiracetam and (S)GABOB from(R)-glyceraldehyde acetonide. Tetrahedron Letters 2013; 54: 2637-2640

11. Switzer JA, Kothari HM, Poizot P, Nakanishi S, Bohannan EW. Enantiospecific electrodeposition of a chiral catalyst. Nature 2003; 425(6957): 490-493

12. Barbara KH. Pharmacologically active compounds in the environment and their chirality. Chem Soc Rev 2010; 39(11): 4466-503

13. Kowalczyk A, Lipiński PFJ, Karoń K, Rode JE, Lyczko K, Dobrowolski JC, Donten M, Kaczorek D, Poszytek J, Kawecki R, Łapkowski M, Malkowska A, Grudzinski IP, Nowicka AM. Enantioselective sensing of (S)-Thalidomide in blood plasma with a chiral naphthalene diimide derivative. Biosens Bioelectron 2020; 167: 112446

14. Lee DS, Ryu HJ, Kim JE, Choi HC, Kim YI, Song HK, Kang TC. The effect of levetiracetam on status epilepticus-induced neuronal death in the rat hippocampus. Seizure 2013; 22(5): 368-77

15. SmithKline B, Chiodini L, Pepeu G. Composition comprising S-oxiracetam for use as nootropic: WO: 9306826, 1993-04-15

16. Li W, Liu HH, Jiang HJ, Wang C, Guo YF, Sun Y, Zhao X, Xiong X, Zhang XH, Zhang K, Nie ZX, Xiaoping Pu XP. (S)-Oxiracetam is the Active Ingredient in Oxiracetam that Alleviates the Cognitive Impairment Induced by Chronic Cerebral Hypoperfusion in Rats. Sci Rep 2017; 7(1):10052

17. Wang C, Dong H, Liu HH, Sun ZY, Yuan AH, Wu JH, Hu YQ. Using HPLC to analyze (S)-oxiracetam and four related substances in the bulk drug of (S)-oxiracetam. J Pharm Biomed Anal 2020;180: 113072 
18. Zhang QY, Yang W, Zhang Q, Yang Y, Li JX, Lu Y, Zheng Y, He JK, Zhao D, Chen XJ. Enantioselective HPLC determination of oxiracetam enantiomers and application to a pharmacokinetic study in beagle dogs. $J$ Chromatogr B 2015; 993-994: 9-13

19. Committee for Proprietary Medical Products (CPMP), Working Parties on Quality, Safety and Efficacy of Medicinal Products, Note for Guidance: Investigation of Chiral Active Substances [III/3501/91], CPMP, Brussells, 1993

20. Smith B, Vandenhende F, DeSante K, Farid NA, Welch PA, Callaghan JT, Forgue ST. Confidence interval criteria for assessment of dose proportionality. Pharm Res 2000; 17(10): 1278-1283

21. Hummel J, McKendrick S, Brindley C, French R. Exploratory assessment of dose proportionality: review of current approaches and proposal for a practical criterion. Pharm Stat , 2009; 8(1): 38-49

22. Villardita C, Grioli S, Lomeo C, Cattaneo C, Parini J. Clinical studies with oxiracetam in patients with dementia of Alzheimer type and multi-infarct dementia of mild to moderate degree.Neuropsychobiology 1992; 25(1): $24-28$

23. Preda L, Alberoni M, Bressi S, Cattaneo C, Parini J, Canal N, Franceschi M. Effects of acute doses of oxiracetam in the scopolamine model of human amnesia. Psychopharmacology (Berl) 1993;110(4): 421-426

24. Bottini G, Vallar G, Cappa S, Monza GC, Scarpini E, Baron P, Cheldi A, Scarlato G. Oxiracetam in dementia: a double-blind, placebo-controlled study. Acta Neurol Scand 1992; 86(3): 237-241

25. Erny GL, Cifuentes A. Liquid separation techniques coupled with mass spectrometry for chiral analysis of pharmaceuticals compounds and their metabolites in biological fluids. J Pharm Biomed Anal 2006; 40(3): 509-515

26. Liu K, Zhong D, Chen X. Enantioselective quantification of chiral drugs in human plasma with LCMS/MS. Bioanalysis 2009; 1(3): 561-576

Tables

Table 1. Demographics and baseline characteristics (mean (SD)) of subjects in part 1, part 2, and part 3

\begin{tabular}{lcllll}
\hline Dose $(\mathrm{g})$ & $\mathrm{n}$ & Age $($ year $)$ & Body weight $(\mathrm{kg})$ & Height $(\mathrm{cm})$ & Body mass index $\left(\mathrm{kg} \cdot \mathrm{m}^{-2}\right)$ \\
\hline Part 1 & & & & & \\
2.0 & 10 & $23.7(3.3)$ & $57.8(6.6)$ & $167.2(8.2)$ & $20.6(1.3)$ \\
4.0 & 10 & $22.1(2.3)$ & $58.6(5.7)$ & $165.6(4.6)$ & $21.4(1.7)$ \\
8.0 & 10 & $22.2(2.9)$ & $58.1(6.3)$ & $165.7(9.4)$ & $21.0(1.1)$ \\
Part 2 & & & & & \\
$3.0 / 6.0$ & 12 & $22.3(1.8)$ & $59.6(8.5)$ & $166.3(7.3)$ & $21.4(1.8)$ \\
$\begin{array}{l}\text { Part } 3 \\
4.0\end{array}$ & 10 & $24.6(3.7)$ & $62.6(9.8)$ & $167.9(8.8)$ & $22.1(1.6)$ \\
\hline
\end{tabular}

Table 2 Comparison of PK parameters between three groups after single-dose administration of S-ORT

\begin{tabular}{llllll}
\hline PK parameters & Unit & Dose & Dose & Dose & P values \\
\hline & & $2.0 \mathrm{~g}(\mathrm{n}=10)$ & $4.0 \mathrm{~g}(\mathrm{n}=10)$ & $8.0 \mathrm{~g}(\mathrm{n}=10)$ & \\
$\mathrm{C}_{\max }$ & $\mu \mathrm{g} / \mathrm{mL}$ & $111.28(18.99)$ & $230.76(29.16)$ & $352.67(42.94)$ & $<0.001$ \\
$\mathrm{AUC}_{0-\mathrm{t}}$ & $\mu \mathrm{g} \cdot \mathrm{h} / \mathrm{mL}$ & $267.09(59.66)$ & $524.50(72.87)$ & $822.68(95.21)$ & $<0.001$ \\
$\mathrm{AUC}_{0-[?]}$ & $\mu \mathrm{g} \cdot \mathrm{h} / \mathrm{mL}$ & $274.72(61.65)$ & $536.06(78.13)$ & $832.07(96.91)$ & $<0.001$ \\
$\mathrm{~T}_{1 / 2}$ & $\mathrm{~h}$ & $5.15(1.74)$ & $5.21(1.62)$ & $4.28(1.23)$ & 0.335 \\
$\mathrm{~T}_{\max }$ & $\mathrm{h}$ & 0.5 & 0.5 & 0.5 & - \\
$\mathrm{V}_{\mathrm{z}}$ & $\mathrm{L}$ & $54.40(16.97)$ & $56.92(19.17)$ & $60.00(19.67)$ & 0.799
\end{tabular}




\begin{tabular}{llllll}
\hline PK parameters & Unit & Dose & Dose & Dose & P values \\
\hline $\mathrm{C}_{\text {max }} /$ dose & $(\mu \mathrm{g} / \mathrm{mL}) / \mathrm{g}$ & $55.64(9.50)$ & $57.69(7.29)$ & $44.08(5.37)$ & 0.001 \\
$\mathrm{AUC}_{0-\mathrm{t}} /$ dose & $(\mu \mathrm{g} \cdot \mathrm{h} / \mathrm{mL}) / \mathrm{g}$ & $133.54(29.83)$ & $131.12(18.22)$ & $102.84(11.90)$ & 0.005 \\
$\mathrm{AUC}_{0-[?] \mathrm{t}} /$ dose & $(\mu \mathrm{g} \cdot \mathrm{h} / \mathrm{mL}) / \mathrm{g}$ & $137.36(30.82)$ & $134.01(19.53)$ & $104.01(12.11)$ & 0.004 \\
\hline
\end{tabular}

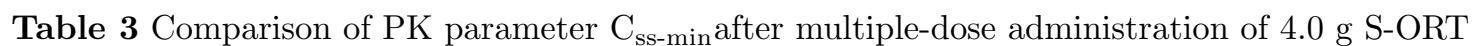

\begin{tabular}{llllll}
\hline PK parameter & Unit & Mean (SD) & Mean $(\mathrm{SD})$ & Mean $(\mathrm{SD})$ & Mean \\
\hline & & Day 5 before dosing $(\mathrm{n}=10)$ & Day 6 before dosing $(\mathrm{n}=10)$ & Day 7 before dosing $(\mathrm{n}=10)$ & $24 \mathrm{~h}$ \\
$\mathrm{C}_{\text {ss-min }}$ & $\mu \mathrm{g} / \mathrm{mL}$ & $3.22(0.68)$ & $3.65(0.88)$ & $3.22(0.78)$ & 3.20( \\
\hline
\end{tabular}

Table 4 Comparison of PK parameters after multiple-dose administration of 4.0 g S-ORT (n=10)

\begin{tabular}{|c|c|c|c|c|}
\hline PK parameters & Unit & Mean (SD) & Mean (SD) & $\mathrm{P}$ Value \\
\hline & & $1^{\text {st }}$ day & $7^{\text {th }}$ day & \\
\hline $\mathrm{C}_{\max }\left(\mathrm{C}_{\mathrm{ss}-\max }\right)$ & $\mu \mathrm{g} / \mathrm{mL}$ & $181.28(24.19)$ & $186.32(28.21)$ & 0.368 \\
\hline $\mathrm{AUC}_{0-\mathrm{t}}\left(\mathrm{AUC}_{\mathrm{ss}}\right)$ & $\mu \mathrm{g} \cdot \mathrm{h} / \mathrm{mL}$ & $551.57(86.35)$ & $577.58(91.07)$ & 0.091 \\
\hline $\mathrm{AUC}_{0-[?]}$ & $\mu \mathrm{g} \cdot \mathrm{h} / \mathrm{mL}$ & $562.71(86.95)$ & $600.71(99.84)$ & 0.054 \\
\hline $\mathrm{T}_{1 / 2}$ & $\mathrm{~h}$ & $4.69(1.92)$ & $6.04(1.87)$ & 0.050 \\
\hline $\mathrm{V}_{\mathrm{z}}$ & $\mathrm{L}$ & $49.28(21.22)$ & $58.28(17.25)$ & 0.105 \\
\hline $\mathrm{T}_{\max }\left(\mathrm{T}_{\mathrm{sS}-\max }\right)$ & $\mathrm{h}$ & 0.5 & 0.5 & - \\
\hline DF & & & $7.70(1.24)$ & \\
\hline $\mathrm{R}_{\mathrm{ac}} *$ & & & $1.05(0.08)$ & \\
\hline
\end{tabular}

The $\mathrm{R}_{\mathrm{ac}}$ in the table is calculated by the ratio the measured $\mathrm{AUC}_{\mathrm{ss}}$ values after reaching steady state on day 7 and $\mathrm{AUC}_{0-24 \mathrm{~h}}$ on day 1

Table 5 Sex difference analysis of PK parameters after single and multiple-dose administration of S-ORT

\begin{tabular}{llllll}
\hline Dose & PK parameters & PK parameters & Mean $(\mathrm{SD})$ & Mean $(\mathrm{SD})$ & $\mathrm{P}$ value \\
\hline & & & Male & Female & \\
& $\mathrm{n}$ & $/$ & 5 & 5 & \\
& $\mathrm{C}_{\max }$ & $\mu \mathrm{g} / \mathrm{mL}$ & $99.79(13.47)$ & $122.77(17.33)$ & $0.047^{*}$ \\
& $\mathrm{AUC}_{0-\mathrm{t}}$ & $\mu \mathrm{g} \cdot \mathrm{h} / \mathrm{mL}$ & $225.65(17.19)$ & $308.53(58.47)$ & $0.016^{*}$ \\
& $\mathrm{AUC}_{0-[?]}$ & $\mu \mathrm{g} \cdot \mathrm{h} / \mathrm{mL}$ & $231.24(18.70)$ & $318.24(58.86)$ & $0.014^{*}$ \\
& $\mathrm{~T}_{1 / 2}$ & $\mathrm{~h}$ single-dose & $4.91(1.78)$ & $5.39(1.87)$ & 0.687 \\
& $\mathrm{CL}_{\mathrm{z}}$ & $\mathrm{L} / \mathrm{h}$ & $8.70(0.69)$ & $6.46(1.19)$ & $0.007^{*}$ \\
& $\mathrm{~V}_{\mathrm{z}}$ & $\mathrm{L}$ & $60.03(19.07)$ & $48.49(14.02)$ & 0.297 \\
& $\mathrm{n}$ & & 5 & 5 & \\
& $\mathrm{C}_{\max }$ & $\mu \mathrm{g} / \mathrm{mL}$ & $237.15(27.34)$ & $224.38(32.61)$ & 0.521 \\
& $\mathrm{AUC}_{0-\mathrm{t}}$ & $\mu \mathrm{g} \cdot \mathrm{h} / \mathrm{mL}$ & $503.98(36.19)$ & $545.01(97.91)$ & 0.405 \\
& $\mathrm{AUC}_{0-[?]}$ g single-dose & $\mu \mathrm{g} \cdot \mathrm{h} / \mathrm{mL}$ & $511.87(43.19)$ & $560.2(102.01)$ & 0.357 \\
& $\mathrm{~T}_{1 / 2}$ & $\mathrm{~h}$ & $4.58(1.57)$ & $5.83(1.57)$ & 0.246 \\
& $\mathrm{CL}_{\mathrm{z}}$ & $\mathrm{L} / \mathrm{h}$ & $7.86(0.65)$ & $7.38(1.64)$ & 0.560 \\
& $\mathrm{~V}_{\mathrm{z}}$ & $\mathrm{L}$ & $51.14(13.59)$ & $62.70(23.64)$ & 0.371 \\
& $\mathrm{n}$ & & 5 & 5 & \\
& $\mathrm{C}_{\max }$ & $\mu \mathrm{g} / \mathrm{mL}$ & $339.46(40.13)$ & $365.88(45.85)$ & 0.361
\end{tabular}




\begin{tabular}{llllll}
\hline Dose & PK parameters & PK parameters & Mean $(\mathrm{SD})$ & Mean $(\mathrm{SD})$ & $\mathrm{P}$ value \\
\hline 8.0 g single-dose & $\mathrm{AUC}_{0-\mathrm{t}}$ & $\mu \mathrm{g} \cdot \mathrm{h} / \mathrm{mL}$ & $776.09(103.22)$ & $869.27(65.67)$ & 0.127 \\
& $\mathrm{AUC}_{0-[?]}$ & $\mu \mathrm{g} \cdot \mathrm{h} / \mathrm{mL}$ & $784.77(102.82)$ & $879.37(70.45)$ & 0.128 \\
& $\mathrm{~T}_{1 / 2}$ & $\mathrm{~h}$ & $4.25(1.37)$ & $4.30(1.23)$ & 0.954 \\
& $\mathrm{CL}_{\mathrm{z}}$ & $\mathrm{L} / \mathrm{h}$ & $10.33(1.27)$ & $9.14(0.74)$ & 0.110 \\
& $\mathrm{~V}_{\mathrm{z}}$ & $\mathrm{L}$ & $63.73(24.74)$ & $56.26(14.93)$ & 0.579 \\
& $\mathrm{n}$ & & 5 & 5 & \\
& $\mathrm{C}_{\max }$ & $\mu \mathrm{g} / \mathrm{mL}$ & $172.47(24.78)$ & $190.10(22.54)$ & 0.273 \\
& $\mathrm{AUC}_{0-\mathrm{t}}$ & $\mu \mathrm{g} \cdot \mathrm{h} / \mathrm{mL}$ & $509.60(83.31)$ & $593.53(73.70)$ & 0.130 \\
Day 1 g multiple-dose & $\mathrm{AUC}_{0-[?]}$ & $\mu \mathrm{g} \cdot \mathrm{h} / \mathrm{mL}$ & $528.57(92.59)$ & $596.86(74.32)$ & 0.234 \\
& $\mathrm{~T}_{1 / 2}$ & $\mathrm{~h}$ & $5.92(2.10)$ & $3.44(0.14)$ & 0.058 \\
& $\mathrm{CL}_{\mathrm{z}}$ & $\mathrm{L} / \mathrm{h}$ & $7.75(1.32)$ & $6.78(0.84)$ & 0.202 \\
& $\mathrm{~V}_{\mathrm{z}}$ & $\mathrm{L}$ & $64.86(19.76)$ & $33.70(3.97)$ & $0.023^{*}$ \\
& $\mathrm{n}$ & & 5 & 5 & \\
4.0 g multiple-dose & $\mathrm{C}_{\mathrm{ss}-\max }$ & $\mu \mathrm{g} / \mathrm{mL}$ & $174.30(23.04)$ & $198.33(29.98)$ & 0.193 \\
& $\mathrm{AUC}_{\mathrm{ss}}$ & $\mu \mathrm{g} \cdot \mathrm{h} / \mathrm{mL}$ & $519.79(40.52)$ & $635.36(93.12)$ & $0.034^{*}$ \\
& $\mathrm{AUC}_{0-[?]}$ & $\mu \mathrm{g} \cdot \mathrm{h} / \mathrm{mL}$ & $539.18(43.74)$ & $662.25(105.11)$ & $0.042^{*}$ \\
& $\mathrm{t}_{1 / 2}$ & $\mathrm{~h}$ & $5.80(2.43)$ & $6.28(1.35)$ & 0.708 \\
& $\mathrm{CL}_{\mathrm{ss}}$ & $\mathrm{L} / \mathrm{h}$ & $7.46(0.60)$ & $6.18(1.07)$ & $0.048^{*}$ \\
& $\mathrm{~V}_{\mathrm{ss}}$ & $\mathrm{L}$ & $61.94(23.82)$ & $54.62(8.30)$ & 0.545 \\
\hline
\end{tabular}

* means $\mathrm{P}$ value is less than 0.05

Table 6 PK parameters of S-ORT after administration of $3.0 \mathrm{~g}$ S-ORT and $6.0 \mathrm{~g}$ racemic ORT

\begin{tabular}{lllll}
\hline PK parameters & & Mean $(\mathrm{SD})$ & Mean $(\mathrm{SD})$ & P value \\
\hline & $/$ & $3.0 \mathrm{~g}$ S-ORT & $6.0 \mathrm{~g}$ ORT & \\
$\mathrm{n}$ & & 12 & 12 & \\
$\mathrm{C}_{\max }$ & $\mu \mathrm{g} / \mathrm{mL}$ & $172.88(31.09)$ & $183.84(37.13)$ & 0.305 \\
$\mathrm{AUC}_{0-\mathrm{t}}$ & $\mu \mathrm{g} \cdot \mathrm{h} / \mathrm{mL}$ & $343.47(53.51)$ & $364.07(66.75)$ & 0.060 \\
$\mathrm{AUC}_{0-[?]}$ & $\mu \mathrm{g} \cdot \mathrm{h} / \mathrm{mL}$ & $363.99(55.45)$ & $386.72(70.61)$ & 0.053 \\
$\mathrm{t}_{1 / 2}$ & $\mathrm{~h}$ & $2.22(0.42)$ & $2.24(0.44)$ & 0.770 \\
$\mathrm{CL}_{\mathrm{z}}$ & $\mathrm{L} / \mathrm{h}$ & $8.43(1.39)$ & $8.00(1.47)$ & 0.11 \\
$\mathrm{~V}_{\mathrm{z}}$ & $\mathrm{L}$ & $26.39(3.11)$ & $25.36(4.03)$ & 0.47 \\
\hline
\end{tabular}

Figure legends

Fig. 1 Structures of S-Oxiracetam(A), R-Oxiracetam(B) and Piracetam (C, internal standard)

Fig. 2 Design and subject allocation scheme for single-dose study in part 1, for chiral pharmacokinetic comparative study in part 2 and for multiple-dose study in part 3

Fig. 3 Mean plasma concentration-time profiles of S-ORT in three single-dose groups ( $\mathrm{n}=10$ for each dose group) (arithmetic scale on the left and logarithmic scale on the right)

Fig. 4 Profile of 48 hours cumulative urine excretion rate after single-dose administration of $4.0 \mathrm{~g}$ S-ORT, $\mathrm{n}=10$

Fig. 5 Mean plasma concentration-time profiles following multiple-dose administration of $4.0 \mathrm{~g}$ S-ORT on day 1 and day $7, \mathrm{n}=10$

Fig. 6 Mean plasma concentrations-time profiles of S-ORT and R-ORT after a single-dose intravenous 
infusion of $6.0 \mathrm{~g}$ racemic ORT injection, $\mathrm{n}=12$ (arithmetic scale on the left and logarithmic scale on the right)

\section{Hosted file}

Figure.pdf available at https://authorea.com/users/367509/articles/486901-a-studyinvestigating-safety-and-pharmacokinetics-of-s-oxiracetam-injection-in-healthyvolunteers 